\title{
Effect of hyposalinity on the infection and pathogenicity of Miamiensis avidus causing scutic- ociliatosis in olive flounder Paralichthys olivaceus
}

\author{
Nanae Takagishi, Tomoyoshi Yoshinaga*, Kazuo Ogawa \\ Department of Aquatic Bioscience, Graduate School of Agricultural and Life Sciences, University of Tokyo, 1-1-1 Yayoi, \\ Bunkyo-ku, Tokyo 113-8657, Japan
}

\begin{abstract}
Miamiensis avidus, a causative agent of scuticociliatosis in olive flounder Paralichthys olivaceus, was previously reported to proliferate the fastest in media with an osmolarity of 300 to $500 \mathrm{mOsm} \mathrm{kg}{ }^{-1}$. This suggests that hyposaline conditions can promote the development of the disease. In the present study, olive flounder constantly showed high mortalities when they were experimentally challenged with the parasite by immersion and subsequently reared in hyposaline conditions. Furthermore, affected flounder produced by the challenge showed symptoms identical to those in naturally infected flounder. It was experimentally demonstrated that hyposaline conditions can be a key factor for the development and outbreak of scuticociliatosis in olive flounder.
\end{abstract}

KEY WORDS: Hyposaline condition · Immersion challenge $\cdot$ Miamiensis avidus $\cdot$ Scuticociliate

\section{INTRODUCTION}

Scuticociliates infect aquatic organisms opportunistically. Outbreaks of scuticociliate infection occur in many fish species, including olive flounder Paralichthys olivaceus (Yoshinaga \& Nakazoe 1993, Kim et al. 2004), turbot Psetta maxima (= Scophthalmus maximus) (Dyková \& Figueras 1994, Sterud et al. 2000, Iglesias et al. 2001, Ramos et al. 2007), sea bass Dicentrarchus labrax (Dragesco et al. 1995), and southern bluefin tuna Thunnus maccoyii (Munday et al. 1997). Mortality is particularly high for olive flounder and turbot, resulting in economic losses in eastern Asia and Europe, respectively. Identification and taxonomy of the scuticociliates infecting these 2 flatfish species and other fish species are often confused. However, recently, Philastrerides dicentrarchi infecting turbot was synonymized with Miamiensis avidus infecting olive flounder, the latter of which was proposed as the name of the major causative agent of scuticociliatosis in the 2 flatfish species (Jung et al. 2007).
The occurrences of scuticociliatosis seem to be influenced by environmental and fish conditions. However, these conditions have not been specified yet. Based on anecdotal evidence, olive flounder suffer from scuticociliatosis more frequently in land-based aquaculture facilities supplied with water from saltwater wells in coastal areas, which generally have lower salinity, than in facilities supplied with coastal waters. Moreover, cultures of scuticociliates proliferate at a faster

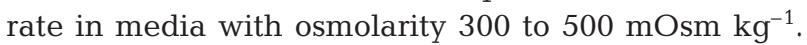
These include Leibovitz's L-15 medium (Alvarez-Pellitero et al. 2004) and proteose peptone and yeast extract dissolved in diluted seawater (Yoshinaga \& Nakazoe 1993). Furthermore, the osmolarity of the body fluid of teleost fishes is regulated at roughly $300 \mathrm{mOsm} \mathrm{kg}^{-1}$ (Marshall \& Grosell 2006), or almost three-tenths of that of ocean water.

Therefore we hypothesized that hyposaline conditions promote the infection and pathogenicity of Miamiensis avidus in olive flounder. The present study was carried out to test this hypothesis. Two challenge 
experiments were conducted to evaluate the effects of low salinity during the challenge and post-challenge rearing periods.

\section{MATERIALS AND METHODS}

Fish. Juvenile olive flounder (mean total length [TL]: $85 \mathrm{~mm}$ ) were purchased from a fish hatchery in the Aichi Prefecture, where fish were reared in saltwater (salinity 31) taken from a saltwater well. The fish were maintained in full-strength natural seawater (SW; salinity 35) in a closed-circuit tank $\left(20^{\circ} \mathrm{C}\right)$ equipped with a biological filter prior to the experiments.

Parasite. We isolated a strain of scuticociliate from the brain of an infected flounder. The parasite was then cloned using the limiting dilution method, and cultured under aseptic conditions. For isolation and routine passage procedures, the ciliates were cultured at $20^{\circ} \mathrm{C}$ in $\mathrm{P} 2 \mathrm{Y} 1-1 / 3 \mathrm{SW}$ medium (proteose-peptone $2 \%$ and yeast extract $1 \%$ dissolved in $1 / 3$ strength SW) supplemented with $5 \%$ fetal bovine serum (FBS). Passages were conducted once a month by subculturing the old culture $(1 \%)$ on fresh medium. The ciliate was identified as Miamiensis avidus by light-microscopic observation of unstained formalin-fixed specimens and silver-impregnated specimens for general morphology and by UV-light microscopic observation of specimens stained with the DNA-binding fluorescent dye, Hoechst 33342, for nuclear morphology, according to morphological characteristics described by Jung et al. (2007). Furthermore, we sequenced the DNA of the small subunit (SSU) ribosomal RNA (rRNA) coding region of the clone following Jung et al. (2005) and obtained $100 \%$ similarity of sequence with that of $M$. avidus (GenBank accession no. AY55080). For the challenge experiments, the ciliates were cultured in P2Y1-1/3 SW, supplemented with 5\% FBS, at $20^{\circ} \mathrm{C}$ for $1 \mathrm{wk}$. At this time, the culture had entered the early stationary phase. The cultures were then centrifuged $(980 \times g, 5 \mathrm{~min})$ and the pellet was re-suspended in either $1 / 3 \mathrm{SW}$ or SW at $10^{3}$ cells $\mathrm{ml}^{-1}$ for challenges. The optimal cell density for the challenge had been determined during our preliminary experiment in which flounder were reared in $1 / 3 \mathrm{SW}$ after being challenged by immersion at $10,10^{2}$, or $10^{3}$ ciliates $\mathrm{ml}^{-1}$ in $1 / 3 \mathrm{SW}$ for $1 \mathrm{~h}$; those challenged at $10^{3}$ ciliates $\mathrm{ml}^{-1}$ showed the highest mortality $(80 \%)$.

Expt 1. This experiment was repeated twice under identical conditions using different batches of ciliates. We used 30 and 31 fish in the first and second trials, respectively. Fish were challenged by immersion in ciliate suspensions (5 1 of $1 / 3 \mathrm{SW}$ containing $10^{3}$ ciliates $\mathrm{ml}^{-1}$ ) at $20^{\circ} \mathrm{C}$ for $1 \mathrm{~h}$. Subsequently, 10 or 11 fish were transferred into 401 of $1 / 3 \mathrm{SW}, 2 / 3 \mathrm{SW}$, or SW in a recirculating aquarium $(60 \times 30 \times 36 \mathrm{~cm})$ equipped with an overhead biofilter. Fish were reared in the aquarium without food at $20^{\circ} \mathrm{C}$. In addition, 10 unchallenged fish were reared in an aquarium containing either 1/3 SW or SW to serve as a negative control. Dead fish were removed from the aquaria daily. During the first trial we examined 5 organs (dorsal muscle of ocular side of body, gills, brain, dorsal fin, and liver) from each of the dead fish under a light microscope to determine the presence or absence of ciliates.

Expt 2. We established 4 treatment groups. Ciliates $\left(10^{3}\right.$ cells $\left.\mathrm{ml}^{-1}\right)$ were suspended in 2.51 of $1 / 3 \mathrm{SW}$ or SW. Forty fish were challenged by immersion in each of the suspensions at $20^{\circ} \mathrm{C}$ for $45 \mathrm{~min}$. Subsequently, the 40 fish from each exposure were divided into 2

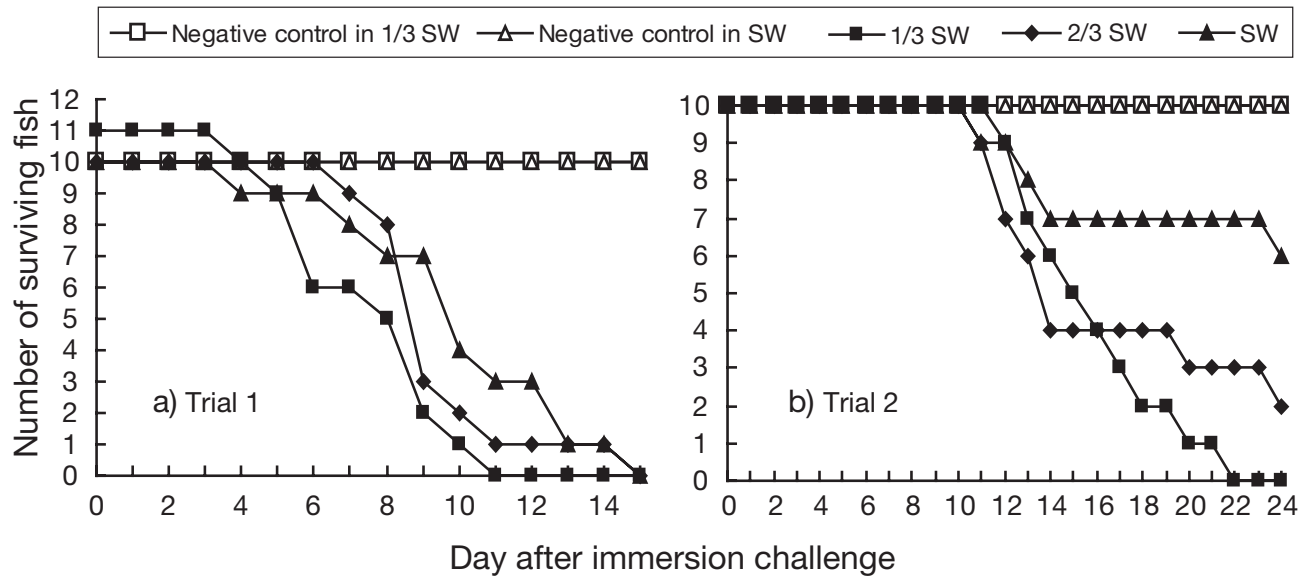

Fig. 1. Miamiensis avidus infecting Paralichthys olivaceus. Expt 1. Mortalities of fish reared in different salinities following a challenge with ciliates in 1/3 strength seawater (SW). The experiments were repeated twice, (a) Trial 1 and (b) Trial 2, using a different batch of ciliates for each trial 
Table 1. Miamiensis avidus infecting Paralichthys olivaceus. Summary of pairwise multiple comparisons of survival curves between experimental groups in Expts 1 and 2. Expt 2 was carried out in duplicate. Log-rank test and the Holm's method were used for multiple comparisons. ID: identical; SW: seawater. ${ }^{*}$ Significantly different $(\mathrm{p}<0.05)$

\begin{tabular}{|c|c|c|c|c|c|c|c|c|c|}
\hline Expt & Group & 1 & 2 & 3 & 4 & 5 & 6 & 7 & 8 \\
\hline Expt 1 (1st trial) & $\begin{array}{l}\text { (1) Negative control in } 1 / 3 \mathrm{SW} \\
\text { (2) Negative control in SW } \\
\text { (3) Challenged in } 1 / 3 \mathrm{SW} \text { and reared in } 1 / 3 \mathrm{SW} \\
\text { (4) Challenged in } 1 / 3 \mathrm{SW} \text { and reared in } 2 / 3 \mathrm{SW} \\
\text { (5) Challenged in } 1 / 3 \mathrm{SW} \text { and reared in SW }\end{array}$ & $\begin{array}{l}\text { ID } \\
* \\
* \\
*\end{array}$ & $\begin{array}{c}\text { ID } \\
{ }^{*} \\
{ }^{*}\end{array}$ & ID & ID & ID & & & \\
\hline Expt 1 (2nd trial) & $\begin{array}{l}\text { (1) Negative control in } 1 / 3 \mathrm{SW} \\
\text { (2) Negative control in SW } \\
\text { (3) Challenged in } 1 / 3 \mathrm{SW} \text { and reared in } 1 / 3 \mathrm{SW} \\
\text { (4) Challenged in } 1 / 3 \mathrm{SW} \text { and reared in } 2 / 3 \mathrm{SW} \\
\text { (5) Challenged in } 1 / 3 \mathrm{SW} \text { and reared in SW }\end{array}$ & $\begin{array}{l}\text { ID } \\
{ }^{*} \\
{ }^{*}\end{array}$ & $\begin{array}{c}\text { ID } \\
{ }^{*} \\
{ }^{*}\end{array}$ & $\begin{array}{l}\text { ID } \\
*\end{array}$ & ID & ID & & & \\
\hline Expt 2 & $\begin{array}{l}\text { (1) Challenged in SW and reared in SW (1) } \\
\text { (2) Challenged in SW and reared in SW (2) } \\
\text { (3) Challenged in SW and reared in } 1 / 3 \mathrm{SW}(1) \\
\text { (4) Challenged in SW and reared in } 1 / 3 \mathrm{SW}(2) \\
\text { (5) Challenged in } 1 / 3 \mathrm{SW} \text { and reared in SW (1) } \\
\text { (6) Challenged in } 1 / 3 \mathrm{SW} \text { and reared in SW (2) } \\
\text { (7) Challenged in } 1 / 3 \mathrm{SW} \text { and reared in } 1 / 3 \mathrm{SW}(1) \\
\text { (8) Challenged in } 1 / 3 \mathrm{SW} \text { and reared in } 1 / 3 \mathrm{SW}(2)\end{array}$ & $\begin{array}{l}\text { ID } \\
{ }^{*} \\
*\end{array}$ & $\begin{array}{c}\text { ID } \\
{ }^{*} \\
*\end{array}$ & $\begin{array}{l}\text { ID } \\
*\end{array}$ & $\begin{array}{c}\text { ID } \\
{ }^{*}\end{array}$ & $\begin{array}{l}\text { ID } \\
{ }^{*}\end{array}$ & $\begin{array}{c}\text { ID } \\
{ }^{*} \\
{ }^{*}\end{array}$ & ID & ID \\
\hline
\end{tabular}

treatment groups that were reared in either $1 / 3 \mathrm{SW}$ or $\mathrm{SW}$ in identical aquaria. Each treatment group was duplicated ( $\mathrm{n}=10$ per group). Fish were reared at $20^{\circ} \mathrm{C}$ without food. We removed dead fish daily.

During the rearing period, the concentrations of ammonia and/or ammonium and nitrite were monitored daily by colorimeter methods using commercial kits (Tetra Test, Tetra Japan).

Statistical analysis. Kaplan-Meier survival curves were drawn and analyzed using the log-rank test. Holm's method was employed for multiple comparisons of survival.

\section{RESULTS}

In Expt 1, fish were challenged in 1/3 SW and subsequently reared in 1/3 SW, 2/3 SW, or SW. There was a trend of mortalities being higher and occurring faster in the lower concentrations of seawater (Fig. 1, Table 1). The trend was clearer in the second trial than in the first trial. Moribund and dead fish developed external symptoms including whitish necrotic patches and hemorrhagic ulcers on the skin and fins.

During the first trial of Expt 1, whitish patches were first noted on the skin of dead fish on Day 5. Most dead fish had between 1 and 4 whitish patches at various sites on the skin. Hemorrhages were first noted in dead fish on Day 8. Twelve of 30 moribund and dead fish had hemorrhages on the skin, fins, or jaws. Necrosis of the caudal fin was observed in 3 fish that died on Day 5 (reared in 1/3 SW), Day 7 (reared in 2/3 SW), and Day
10 (reared in SW). Furthermore, we found ciliates in the dorsal muscle of the ocular side of body, gills, brain, dorsal fin, and liver in $7,60,33,77$, and $10 \%$ of dead fish, respectively.

In Expt 2, fish reared in 1/3 SW after the challenges showed high mortalities, irrespective of whether they had been challenged in 1/3 SW or full-strength SW (Fig. 2, Table 1). On the other hand, fish reared in SW

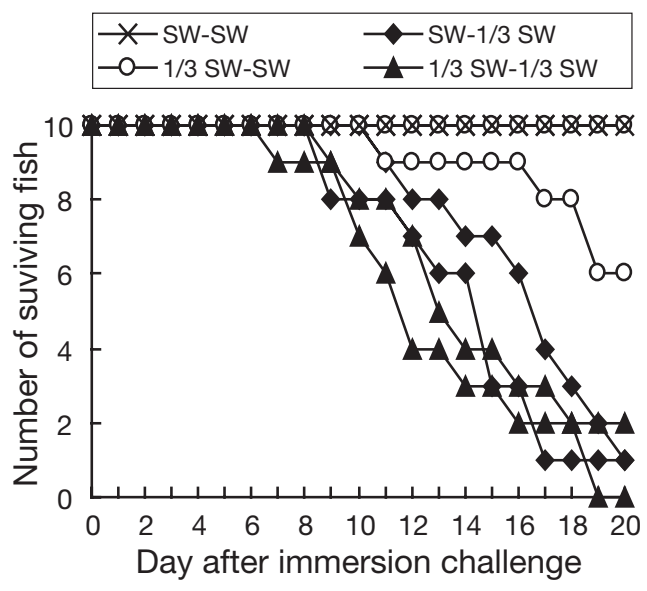

Fig. 2. Miamiensis avidus infecting Paralichthys olivaceus. Expt 2. Mortalities of fish challenged and reared in $1 / 3$ strength seawater (SW) and full-strength SW. Four treatments were tested: challenge in SW and rearing in SW (SW - SW); challenge in 1/3 SW and rearing in SW (1/3 SW - SW); challenge in SW and rearing in 1/3 SW (SW - 1/3 SW); and challenge in $1 / 3 \mathrm{SW}$ and rearing in $1 / 3 \mathrm{SW}(1 / 3 \mathrm{SW}-1 / 3 \mathrm{SW})$. The experiment was carried out in duplicate 
had significantly higher survival compared with fish reared in $1 / 3 \mathrm{SW}$, irrespective of whether they had been challenged in 1/3 SW or SW (Table 1). In this experiment, moribund and dead fish frequently displayed the same external symptoms as those in Expt 1.

During both experiments, the concentrations of ammonia and/or ammonium and nitrite remained at harmless levels of below $0.5 \mathrm{ppm}$, respectively, in all aquaria.

\section{DISCUSSION}

In turbot, injection or immersion after abrasion were needed to obtain high mortalities in challenge experiments with Philasterides dicentrarchi (= Miamiensis avidus). Parama et al. (2003) challenged turbot by immersion after artificial abrasion, periorbital injection, intramuscular injection, and intraperitoneal injection. In their experiment, $60 \%$ mortality was obtained in the immersion challenge and $100 \%$ mortalities were obtained in other challenges. Puig et al. (2007) reported up to $66.7 \%$ mortality in fish injected with 40000 ciliates. In olive flounder, Jung et al. (2007) and Song et al. (2009) reported $100 \%$ and 30 to $100 \%$ mortalities respectively in an immersion challenge with $M$. avidus, although the salinities of the seawater in their trials were not described.

In the present study, mortalities higher than $80 \%$ were experimentally obtained in olive flounder in hyposaline conditions. During Expt 1, mortalities were higher and faster in fish reared in hyposaline conditions than those in SW, although a considerable difference was observed in mortalities between Trials 1 and 2. During Expt 2, holding fish at a low salinity $(1 / 3 \mathrm{SW})$ showed a significant effect on mortality irrespective of the salinities in the challenges. Our results suggest that rearing in hyposaline conditions can induce scuticociliatosis and resulting high mortality in flounder.

The high mortalities at lower salinities may be explained in 3 ways. First, the lower salinities may have favored the propagation of scuticociliates on the fish surface and in the aquaria, as seen in the propagation media (Yoshinaga \& Nakazoe 1993). It is likely that the scuticociliates were propagated in the overhead filter, although the ciliate densities in the filter were not examined. Organic substances trapped in the filter would provide an abundant source of food. The difference in mortalities between the first and second trials in Expt 1 may be attributable to differences in the propagation rates of the scuticociliates in the filters as well as tank effects and differences in ciliate batches and fish lots. Second, the scuticociliates may have increased their pathogenicity or at least their invading capacity in hyposaline waters. Third, the olive flounder may have been stressed by the lower salinity, which would increase susceptibility to infection. The first explanation seems the most plausible, but effects of hyposalinity on parasite pathogenicity and on host susceptibility deserve further study.

The primary sites of infection were divided into 3 categories: (1) the body surface, including skin, gills, and fin; (2) the brain; and (3) other internal organs, including muscle and viscera (Dyková \& Figueras 1994, Iglesias et al. 2001, Kim et al. 2004). In the present study, infections with the scuticociliates were found in the skin, fins, gills, muscle, liver, and brain. Exposure to ciliates via immersion in a hyposaline environment resulted in an infection that was very similar to a natural infection.

In conclusion, the present study has demonstrated that lower-salinity conditions can be a key factor for outbreaks of scuticociliatosis in olive flounder, and suggests that avoiding the use of hyposaline seawater may lead to reduction of mortalities of olive flounder by scuticociliatosis in aquaculture farms.

\section{LITERATURE CITED}

Alvarez-Pellitero P, Palenzuela O, Padros F, Sitja-Bobadilla A, Riaza A, Silva R, Aran J (2004) Histophagous scuticociliatids (Ciliophora) parasitizing turbot Scophthalmus maximus: morphology, in vitro culture and virulence. Folia Parasitol 51:177-187

Dragesco A, Dragesco J, Coste F, Gasc C, Romestand B, Raymond JC, Bouix G (1995) Philasterides dicentrarchi, n. sp. (Ciliophora, Scuticociliatida), a histophagous opportunistic parasite of Dicentrarchus labrax (Linnaeus, 1758), a reared marine fish. Eur J Protistol 31:327-340

Dyková I, Figueras A (1994) Histopathological changes in turbot Scophthalmus maximus due to a histophagous ciliate. Dis Aquat Org 18:5-9

Iglesias R, Parama A, Alvarez MF, Leiro J, Fernandez J, Sammartin ML (2001) Philasterides dicentrarchi (Ciliophora, Scuticociliatida) as the causative agent of scuticociliatosis in farmed turbot Scophthalmus maximus in Galicia (NW Spain). Dis Aquat Org 46:47-55

Jung SJ, Kitamura SI, Song JY, Joung IY, Oh MJ (2005) Complete small subunit rRNA gene sequence of the scuticociliate Miamiensis avidus pathogenic to olive flounder Paralichthys olivaceus. Dis Aquat Org 64:159-162

Jung SJ, Kitamura SI, Song JY, Oh MJ (2007) Miamiensis avidus (Ciliophora: Scuticociliatida) causes systemic infection of olive flounder Paralichthys olivaceus and is a senior synonym of Philasterides dicentrarchi. Dis Aquat Org 73: $227-234$

Kim SM, Cho JB, Kim SK, Nam YK, Kim KH (2004) Occurrence of scuticociliatosis in olive flounder Paralichthys olivaceus by Phiasterides dicentrarchi (Ciliophora: Scuticociliatida). Dis Aquat Org 62:233-238

Marshall WS, Grosell M (2006) Ion transports, osmoregulation, and acid-base balance. In: Evans DH, Claiborne JB (eds) The physiology of fishes, 3rd edn. CRC Press, Taylor \& Francis Group, Boca Raton, FL, p 177-230 
Munday BL, Odonoghue PJ, Watts M, Rough K, Hawkesford $T$ (1997) Fatal encephalitis due to the scuticociliate Uronema nigricans in sea-caged, southern bluefin tuna Thunnus maccoyii. Dis Aquat Org 30:17-25

Parama A, Iglesias R, Alvarez MF, Leiro J, Aja C, Sanmartin ML (2003) Philasterides dicentrarchi (Ciliophora, Scuticociliatida): experimental infection and possible routes of entry in farmed turbot (Scophthalmus maximus). Aquaculture 217:73-80

Puig L, Traveset R, Palenzuela O, Padros F (2007) Histopathology of experimental scuticociliatosis in turbot Scophthalmus maximus. Dis Aquat Org 76:131-140

Ramos MF, Costa AR, Barandela T, Saraiva A, Rodrigues PN (2007) Scuticociliate infection and pathology in cultured

Editorial responsibility: Dieter Steinhagen,

Hannover, Germany turbot Scophthalmus maximus from the north of Portugal. Dis Aquat Org 74:249-253

Song JY, Kitamura SI, Oh MJ, Kang HS, Lee JH, Tanaka SJ, Jung SJ (2009) Pathogenicity of Miamiensis avidus (syn. Philasterides dicentrarchi), Pseudocohnilembus persalinus, Pseudocohnilembus hargisi and Uronema marinum (Ciliophora, Scuticociliatida). Dis Aquat Org 83:133-143

Sterud E, Hansen MK, Mo TA (2000) Systemic infection with Uronema-like ciliates in farmed turbot, Scophthalmus maximus (L.). J Fish Dis 23:33-37

Yoshinaga T, Nakazoe J (1993) Isolation and in vitro cultivation of an unidentified ciliate causing scuticociliatosis in Japanese flounder (Paralichthys olivaceus). Fish Pathol 28: 131-134

Submitted: December 4, 2008; Accepted: July 9, 2009 Proofs received from author(s): September 6, 2009 